\title{
Low rectal cancer: current approach based on magnetic resonance imaging
}

\author{
Câncer de reto inferior: abordagem atual baseada na ressonância magnética \\ Marcus Valadão1, Eduardo R. Z. Câmara1, Rodrigo Araújo', José Paulo Jesus', Eduardo Linhares', Claudia \\ Carrada ${ }^{1}$
}

\begin{abstract}
The complex anatomy surrounding lower rectal cancer, as well as its aggressive biological behavior, creates surgical challenges. Furthermore, patients with lower rectal cancer have a poorer prognosis, compared to tumors in the middle and upper rectum. Thus, it is essential to adopt new strategies to optimize the results of surgical treatment. Magnetic resonance imaging has become a crucial tool for successfully selecting and completing surgery, as it provides a high anatomical resolution and the ability to define the tumor's relationship with the sphincter complex. New surgical techniques based on magnetic resonance imaging can also improve patients' oncological and functional outcomes. This review examines the modern approach to treating lower rectal cancer, and aims to simplify the complex decisions that surgery currently requires. The PubMed database was searched using the terms "lower rectal cancer", "colorectal surgery", and "magnetic resonance imaging". Milestone reports from recent years have been addressed in this review.
\end{abstract}

Keywords: Rectal neoplasms/surgery; Colorectal surgery; Colorectal neoplasms; Magnetic resonance imaging

\begin{abstract}
RESUMO
O câncer do reto inferior representa um desafio ao cirurgião, principalmente relacionada a complexidade anatômica e cirúrgica dessa região, além da questão biológica, visto que pacientes portadores de câncer do reto inferior apresentam pior resultado oncológico quando comparados aos tumores de reto médio e superior. Nesse contexto, torna-se fundamental a adoção de novas estratégias que visem a otimizar os resultados do seu tratamento. Nesse sentido, devido a alta resolução anatômica e a capacidade de definir a relação do tumor com o complexo esfincteriano, a ressonância magnética (RM) tornou-se ferramenta crucial para a escolha e sucesso da cirurgia. Além disso, novas técnicas cirúrgicas com base nas infor-
\end{abstract}

1. Instituto Nacional de Cancer José Alencar Gomes da Silva - INCA, Rio de Janeiro, RJ, Brazil.

Conflicts of interest: no

Financial support: For the accomplishment of this work there was no aid or financial resources.

Corresponding author: Marcus Valadão

Brazilian National Institute of Cancer. Praça da Cruz Vermelha, 9, Centro, Rio de Janeiro, RJ, Brazil. Zip code: 20230-130. Phone: +55 $2198103-9232$

E-mail: mvaladao@inca.gov.br

Received on: July 30, 2017 | Accepted on: September 6, 2017

DOI: 10.26790/BJO20171345A133 
mações da ressonância tem propiciado melhores resultados oncológicos e funcionais para esses pacientes. O presente artigo revisa a abordagem moderna do câncer de reto inferior e tem o intuito de tornar mais simples a complexa decisão de como tratar cirurgicamente nos dias atuais esse tumor. Esse trabalho foi realizado com base na pesquisa no pubmed utilizando os termos "low rectal cancer", "colorectal surgery", magnetic ressonance imaging". Os artigos considerados importantes marcos nesse assunto nos últimos anos foram abordados.

Descritores: Neoplasias retais/cirurgia; Cirurgia colorretal; Neoplasias colorretal; Imagem por ressonância magnética

\section{INTRODUCTION}

The rectum is a $15-\mathrm{cm}$ section of the gastrointestinal tract that extends from the anal canal to the rectosigmoid junction, and is divided into upper, middle, and lower segments. The upper, middle, and lower segments are approximately $10-15 \mathrm{~cm}, 5-10 \mathrm{~cm}$, and $0-5 \mathrm{~cm}$ from the anal verge, respectively. ${ }^{(1)}$ Lower rectal tumors appear to be more aggressive and are associated with high rates of positive radial margins, local recurrence, and mortality, which are related to the complex anatomy of the rectum. For example, these tumors are located near the pelvic organs, the sphincter complex, the narrowing of the bony pelvis, and the progressive tapering of the mesorectum caudal to its encounter with the levator muscle of the anus. $^{(2-4)}$ (Figure 1)

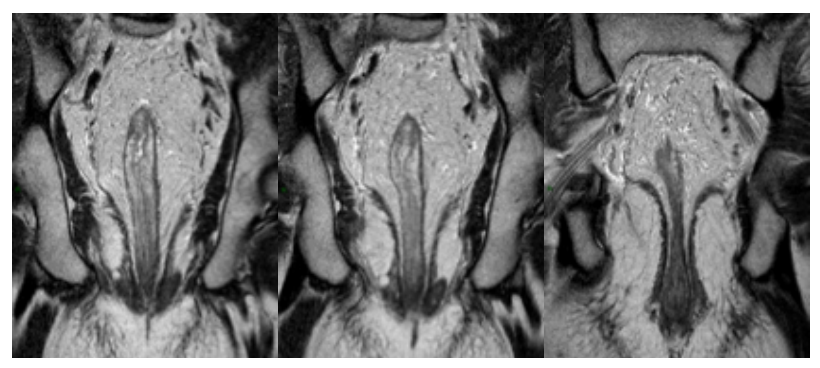

Figure 1. T2-weighted coronal sections demonstrating the anatomy of the inferior rectus and sphincter complex.

Previous studies have revealed that abdominoperineal resection for lower rectal tumors is associated with a poorer prognosis, compared to lower anterior resection, based on the $30 \%$ higher risk of tumor perforation and high rates of positive radial margins $(0-10 \%){ }^{(5-9)}$ Furthermore, patients with lower rectal cancer who receive neoadjuvant chemoradiotherapy have shorter disease-free survival, even after achieving a complete pathological response, compared to patients with upper and middle rectal tumors. ${ }^{(10)}$
Thus, it is important to adopt new strategies that aim to optimize the outcomes of treatment for lower rectal cancer. Magnetic resonance imaging (MRI) has become a crucial tool for successfully selecting and completing surgery, based on its high anatomical resolution and ability to define the tumor's relationship with the sphincter complex.

\section{Developments}

This article is a narrative review that evaluates the modern approach to surgically treating lower rectal cancer based on MRI findings. The PubMed database was searched using the terms "lower rectal cancer", "colorectal surgery", and "magnetic resonance imaging". Milestone reports from 2001 to 2017 were selected to be addressed in this review, choosing the most recent articles to carry out a current revision.

This study was submitted to and approved by the INCA Research Ethics Committee. Images taken from articles included in the literature review were authorized for the use in this article.

\section{Staging based in MRI}

Shihab et al. have proposed specific criteria for staging lower rectal tumors based on MRI findings, which helps the surgeon select the resection type and degree of sphincter preservation..$^{(2,8,11)}$ Lower rectal tumors are stratified into three levels based on coronal T2-weighted images:

- Level 1 or supra-levator: the tumor is above the insertion of the levator ani. At this level, the mesorec- 
tal fat is clearly visible. Total mesorectal excision with lower colorectal anastomosis is indicated for tumors with $\leq 1 \mathrm{~mm}$ of extension into the mesorectal fascia. Broader resection is indicated for cases with involvement of the mesorectal fascia or adjacent structures.

- Level 2 or intra-levator: the tumor is between the origin of the levator ani and the upper margin of the puborectal muscle. At this level, there is progressive tapering of the mesorectal fat and the evaluation of radial tumor extension is crucial. Intersphincteric resection is indicated for tumors that are limited to the muscularis propria or tumors with extension to the interphincteric plane up to $1 \mathrm{~mm}$ from the levator ani. Extra-elevator abdominoperineal resection is indicated for tumors with a potentially positive radial margin (i.e., invasion or $<1 \mathrm{~mm}$ from the levator ani).

- Level 3 or infra-levator: the tumor is at or below the puborectal muscle. This region (the anal canal) is devoid of mesorectum, with an inner sphincter that is formed by the lower segment of the circular muscular layer of the distal rectum and an external sphincter that is formed of the puborectal fibers as they join the lower portion of the levator ani.(12) Inter-sphincter resection can be performed when there is extension of $\leq 1 \mathrm{~mm}$ from the outer margin of the internal sphincter, while extra-elevator abdominoperineal resection is indicated for cases with greater involvement of the intersphincteric plane or the external sphincter. $(2,8,11)$

There is also a proposal for staging lower rectal cancer according to the involvement of the sphincter complex structures (Figures 2 and 3). ${ }^{(3,4)}$

- Stage 1: tumors confined to the rectal wall without involvement of the entire muscle's thickness.

- Stage 2: tumors that involve the entire muscular layer of the internal sphincter but without extension to the intersphincteric plane. When the tumor is above the sphincter, it is confined to the mesorectum.

- Stage 3: tumors that invade the intersphincteric plane but maintain a distance of $\geq 1 \mathrm{~mm}$ from the levator ani.
- Stage 4: tumors that invade the external sphincter or are $<1 \mathrm{~mm}$ from the levator ani. The tumor may or may not have invaded the adjacent organs.

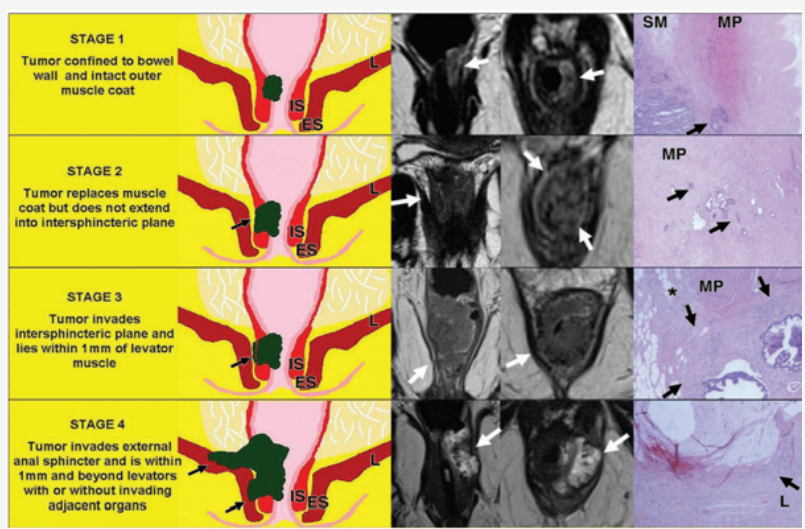

Figure 2. Coronal MRI cut-off scheme of staging of lower rectum tumors by Shihab et al.(10) Figure published by Nougaret et al. ${ }^{(4)}$ IS: internal sphincter; ES: external sphincter; EA: anus lift.

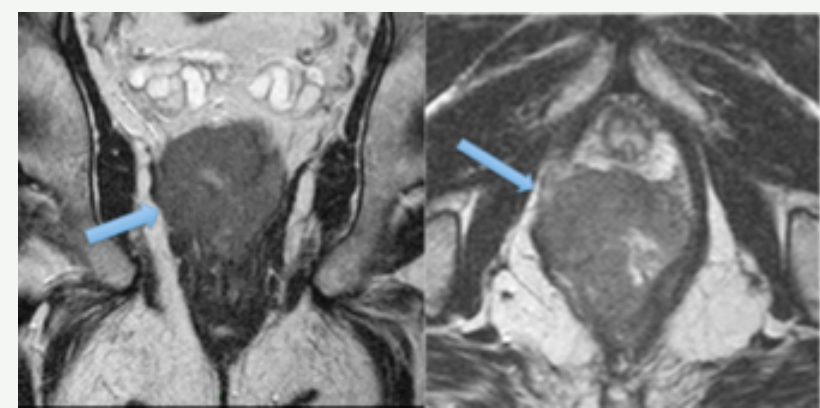

Figure 3. Tumor invading the levator ani and puborectal muscle on the right. Coronal and axial T2-weighted cuts (Stage 4, according to Nougaret et al. Staging proposal). ${ }^{(4)}$

\section{Therapeutic strategy}

Shihab et al. have also proposed a therapeutic strategy that addresses this staging proposal. Neoadjuvant treatment is indicated for more advanced tumors (Stages 3 and 4), in an attempt to achieve tumor regression to Stages 1 or 2, which would allow for intersphincteric resection with anal preservation. ${ }^{(3,4)}$ Figure 4 shows the modified scheme of different surgical techniques that can be used to treat lower rectal cancer. 


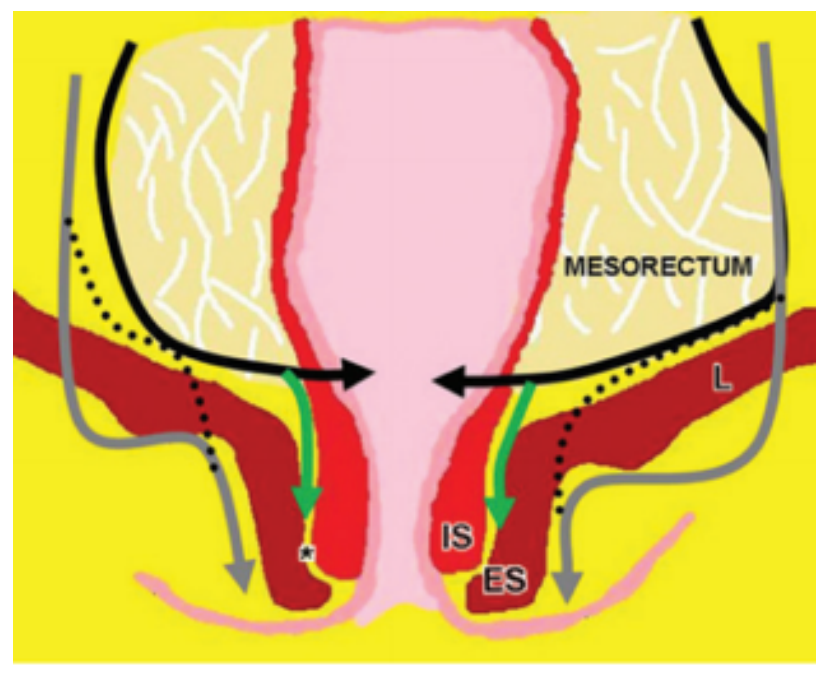

Figure 4. Modified scheme of the different surgical techniques for lower rectum. Figure published by Nougaret et al.(4) IS: internal sphincter; ES: external sphincter; L: levator muscle of the anus, *: interphincteric plane. Black line: low anterior resection (rectum and mesorectum in block). Green line: Low anterior resection with inter-sphincter resection. Dotted line: Conventional abdominoperineal resection. Gray line: Extra-elevated abdominoperineal resection.

\section{Comments}

The previous articles have clearly highlighted the value of MRI for guiding rectal cancer treatment, especially in cases of lower rectal cancer. In addition, it is important to request MRI results from before and after neoadjuvant treatment, in order to ensure that an accurate comparison can be used to evaluate the clinical response, disease progression, and possibility of sphincter preservation. Furthermore, post-treatment imaging is commonly performed because it can alter the treatment choice in up to $32 \%$ of cases. (13-18) Moreover, preoperative MRI should ideally be performed 8 weeks after the end of the neoadjuvant treatment (chemoradiotherapy), as the response rate appears to be related to time. ${ }^{(19-21)}$ At the Brazilian National Cancer Institute, our conduct matches the literature with MRI being performed pretreatment and again 8 weeks after neoadjuvant therapy. Surgery is performed 10-12 weeks after neoadjuvant therapy.

The National Cancer Institute uses a similar classi- fication for assessing involvement of the sphincter complex (Table 1), and this classification was useful for therapeutic decision-making. A preliminary analysis of our study (INCAGI004) revealed that sphincter involvement before and after neoadjuvant treatment was associated with the type of surgery that was performed for 49 patients. In that series, $42 \%$ of patients with intersphincteric plane involvement (Grade 2) underwent sphincter-preserving surgery after neoadjuvant treatment, whereas only $20 \%$ of patients with external sphincter involvement (Grade 3 ) in the baseline MRI underwent sphincter-preserving surgery. The final analysis is currently being performed and we hope to publish the results. These MRI-based classifications appear to help guide the selection of surgical treatment for patients with lower rectal cancer, which can help provide better outcomes with fewer sequelae.

Table 1. Degree of sphincter impairment and type of operation indicated

\begin{tabular}{l|l}
\hline $\begin{array}{l}\text { Involvement of the sphincter } \\
\text { complex }\end{array}$ & Therapeutic decision \\
\hline $\begin{array}{l}\text { Grade 0: No involvement } \\
\text { Grade 1: Internal sphincter } \\
\text { involvement }\end{array}$ & Low anterior resection \\
\hline $\begin{array}{l}\text { Grade 2: Intersphincteric } \\
\text { plane }\end{array}$ & $\begin{array}{l}\text { Conventional } \\
\text { abdominoperineal resection }\end{array}$ \\
\hline $\begin{array}{l}\text { Grade 3: External sphincter } \\
\text { involvement }\end{array}$ & $\begin{array}{l}\text { Conventional } \\
\text { abdominoperineal resection }\end{array}$ \\
\hline
\end{tabular}

In summary, the current treatment of lower rectal cancer should be decided based on the anatomical features evaluated by the high resolution resonance. The new strategies of sphincter preservation can be applied as long as they are guided by good quality images, allowing to reduce the rate of mutilating surgeries (abdominoperineal resection) without prejudice to oncological results.

\section{Acknowledgment}

We gratefully acknowledge the support of Doctor Rafael Albagli, without which the present study could not have been completed. 


\section{REFERENCES}

1. lafrate $F$, Laghi A, Paolantonio $P$, Rengo $M$, Mercantini $P$, Ferri M, Ziparo V,Passariello R. Preoperative staging of rectal cancer with MR Imaging: correlation with surgical and histopathologic findings. Radiographics. 2006;26(3):701-14. Review.

2. Shihab OC, How P, West N, George C, Patel U, Quirke P, Heald RJ, Moran BJ,Brown G. Can a novel MRI staging system for low rectal cancer aid surgical planning? Dis Colon Rectum. 2011;54(10):1260-4.

3. Shihab OC, Taylor F, Salerno G, Heald RJ, Quirke P, Moran BJ, Brown G. MRI predictive factors for long-term outcomes of low rectal tumours. Ann Surg Oncol. 2011;18(12):3278-84.

4. Nougaret S, Reinhold C, Mikhael HW, Rouanet P, Bibeau F, Brown G. The use of MR imaging in treatment planning for patients with rectal carcinoma: have youchecked the "DISTANCE"? Radiology. 2013;268(2):330-44.

5. Kapiteijn E, Marijnen CA, Nagtegaal ID, Putter $H$, Steup WH, Wiggers T, Rutten HJ, Pahlman L, Glimelius B, van Krieken JH, Leer JW, van de Velde CJ; Dutch Colorectal Cancer Group. Preoperative radiotherapy combined with total mesorectal excision for resectable rectal cancer. N Engl J Med. 2001;345(9):638-46.

6. Nagtegaal ID, van de Velde CJ, Marijnen CA, van Krieken JH, Quirke P; Dutch Colorectal Cancer Group; Pathology Review Committee. Low rectal cancer: a call for a change of approach in abdominoperineal resection. J Clin Oncol. 2005;23(36):9257-64.

7. Salerno G, Daniels IR, Brown G. Magnetic resonance imaging of the low rectum: defining the radiological anatomy. Colorectal Dis. 2006;8 Suppl 3:10-3. Review.

8. Shihab OC, Heald RJ, Rullier E, Brown G, Holm T, Quirke P, Moran BJ. Defining the surgical planes on MRI improves surgery for cancer of the low rectum. Lancet Oncol. 2009;10(12):1207-11.

9. Kusters M, Marijnen CA, van de Velde CJ, Rutten $\mathrm{HJ}$, Lahaye MJ, Kim JH,Beets-Tan RG, Beets GL. Patterns of local recurrence in rectal cancer; a study of the Dutch TME trial. Eur J Surg Oncol. 2010;36(5):470-6.

10. Araujo RO, Valadão $M$, Borges $D$, Linhares $E$, de Jesus JP, Ferreira CG,Victorino AP, Vieira FM, Albagli R. Nonoperative management of rectal câncer after chemoradiation opposed to resection after complete clinical response. A comparative study. Eur J Surg Oncol. 2015;41(11):1456-63.

11. Shihab OC, Moran BJ, Heald RJ, Quirke P, Brown G. MRI staging of low rectal cancer. Eur Radiol. 2009;19(3):643-50.
12. Taylor FG, Swift RI, Blomqvist L, Brown G. A systematic approach to the interpretation of preoperative staging MRI for rectal cancer. AJR Am J Roentgenol. 2008;191(6):1827-35.

13. McBrearty A, McCallion K, Moorehead RJ, McAllister I, Mulholland K, Gilliland R, Campbell WJ. Re-Staging Following Long-Course Chemoradiotherapy For Rectal Cancer: Does It Influence Management? Ulster Med J. 2016;85(3):178-81.

14. Engin G, Sharifov R. Magnetic resonance imaging for diagnosis and neoadjuvant treatment evaluation in locally advanced rectal cancer: A pictorial review. World J Clin Oncol. 2017;8(3):214-29.

15. De Nardi P, Carvello M. How reliable is current imaging in restaging rectal cancer after neoadjuvant therapy? World J Gastroenterol. 2013;19(36):5964-72. Review.

16. Lee JH, Jang HS, Kim JG, Lee MA, Kim DY, Kim TH, et al. Prediction of pathologic staging with magnetic resonance imaging after preoperative chemoradiotherapy in rectal cancer: pooled analysis of KROG 10-01 and 11-02. Radiother Oncol.2014;113(1):18-23.

17. Hanly AM, Ryan EM, Rogers AC, McNamara DA, Madoff RD, Winter DC; MERRION Study Group. Multicenter Evaluation of Rectal cancer Relmaging pOst Neoadjuvant(MERRION) Therapy. Ann Surg. 2014;259(4):723-7.

18. Zhao RS, Wang H, Zhou ZY, Zhou Q, Mulholland MW. Restaging of locally advanced rectal cancer with magnetic resonance imaging and endoluminal ultrasound after preoperative chemoradiotherapy: a systemic review and meta-analysis. Dis Colon Rectum. 2014;57(3):388-95.

19. Balyasnikova S, Brown G. Optimal Imaging Strategies for Rectal Cancer Staging and Ongoing Management. Curr Treat Options Oncol. 2016;17(6):32. Review.

20. Probst CP, Becerra AZ, Aquina CT, Tejani MA, Wexner SD, Garcia-Aguilar J,Remzi FH, Dietz DW, Monson JR, Fleming FJ; Consortium for Optimizing the Surgical Treatment of Rectal Cancer (OSTRiCh). Extended Intervals after Neoadjuvant Therapy in Locally Advanced Rectal Cancer: The Key to Improved Tumor Response and Potential Organ Preservation. J Am Coll Surg. 2015;221(2):430-40.

21. KSAR Study Group for Rectal Cancer. essential items for structured reporting of rectal cancer MRI: 2016 Consensus Recommendation from the Korean Society of Abdominal Radiology. Korean J Radiol. 2017;18(1):132-51. 